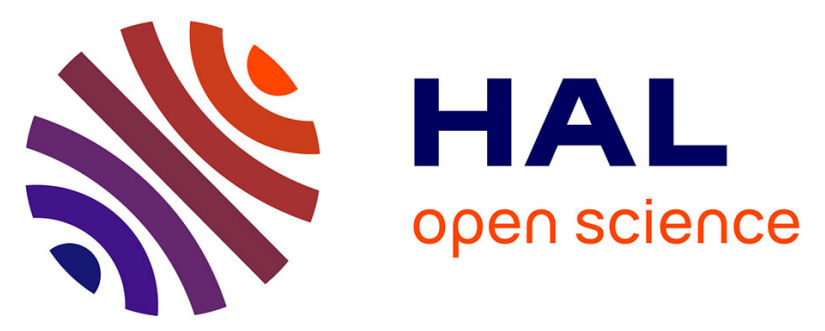

\title{
Influence of Arctic polar ozone depletion on lower stratospheric ozone amounts at Haute-Provence Observatory $\left(43.92^{\circ} \mathrm{N}, 5.71^{\circ} \mathrm{E}\right)$
}

Sophie Godin, Marion Marchand, Alain Hauchecorne, Franck Lefèvre

\section{- To cite this version:}

Sophie Godin, Marion Marchand, Alain Hauchecorne, Franck Lefèvre. Influence of Arctic polar ozone depletion on lower stratospheric ozone amounts at Haute-Provence Observatory $\left(43.92^{\circ} \mathrm{N}\right.$, $5.71^{\circ} \mathrm{E}$ ). Journal of Geophysical Research: Atmospheres, 2002, 107 (D20), pp.SOL 14-1-SOL 14-11. 10.1029/2001JD000516 . insu-03112003

\section{HAL Id: insu-03112003 https://hal-insu.archives-ouvertes.fr/insu-03112003}

Submitted on 15 Jan 2021

HAL is a multi-disciplinary open access archive for the deposit and dissemination of scientific research documents, whether they are published or not. The documents may come from teaching and research institutions in France or abroad, or from public or private research centers.
L'archive ouverte pluridisciplinaire HAL, est destinée au dépôt et à la diffusion de documents scientifiques de niveau recherche, publiés ou non, émanant des établissements d'enseignement et de recherche français ou étrangers, des laboratoires publics ou privés. 


\title{
Influence of Arctic polar ozone depletion on lower stratospheric ozone amounts at Haute-Provence Observatory $\left(43.92^{\circ} \mathrm{N}, 5.71^{\circ} \mathrm{E}\right)$
}

\author{
S. Godin, M. Marchand, A. Hauchecorne, and F. Lefèvre \\ Service d'Aéronomie CNRS, Université de Pierre et Marie Curie, Paris, France \\ Received 8 February 2001; revised 20 June 2001; accepted 24 July 2001; published 11 September 2002.
}

[1] Lidar and ozone sonde measurements performed at Haute-Provence Observatory are used together with a high-resolution potential vorticity (PV) transport model to study the influence of Arctic polar vortex ozone depletion on ozone amounts at this location prior to vortex dilution. The study focuses on four Arctic winters from 1996 to 2000. The transport model is used to investigate the presence of polar air masses above the station. These air masses, which are characterized by high PV values, can extend toward midlatitude regions during winter. Polar air masses are detected using a daily threshold value defined from the PV fields. The monthly average fraction of polar air generally increases with altitude from a few percent in the lower stratosphere to $10 \%$ or more above $500 \mathrm{~K}$. The source of presence of polar air is largely dominated by filament events in the lower stratosphere and is equally divided between filaments and vortex excursions above the station in the middle stratosphere. The presence of polar air above the station shows high interannual variability. In the winter of 1999/2000 the least amount of polar air was detected above the station. However, vortex excursions above the station from January to March 2000 led to a significant average ozone reduction, estimated to $1.6 \%$ in the $400-650 \mathrm{~K}$ potential temperature range using a chemical transport model (CTM) evaluation of ozone loss at the vortex edge. Cold vortex, such as observed in 1999/2000, results in less transport toward midlatitude, but strong ozone depletion within the vortex combined with transient excursions of polar air can have a significant impact on ozone amounts in the midlatitude regions. INDEX TERMS: 0340 Atmospheric Composition and Structure: Middle atmosphere - composition and chemistry; 0341 Atmospheric Composition and Structure: Middle atmosphere-constituent transport and chemistry (3334); 1610 Global Change: Atmosphere (0315, 0325); 3334 Meteorology and Atmospheric Dynamics: Middle atmosphere dynamics (0341, 0342); 3337

Meteorology and Atmospheric Dynamics: Numerical modeling and data assimilation; KEYWORDS: ozone depletion, Arctic, stratosphere, lidar, polar filament, northern midlatitudes

Citation: Godin, S., M. Marchand, A. Hauchecorne, and F. Lefèvre, Influence of Arctic polar ozone depletion on lower stratospheric ozone amounts at Haute-Provence Observatory (43.92 ${ }^{\circ}$ N, 5.71 $\left.{ }^{\circ} \mathrm{E}\right)$, J. Geophys. Res., 107(D20), 8272, doi:10.1029/2001JD000516, 2002.

\section{Introduction}

[2] One of the hypothesis advanced to explain the seasonality of the trends of decreasing stratospheric ozone in the Northern hemisphere, involves the erosion of the Arctic polar vortex due to planetary wave disturbances at the vortex edge [Tuck et al., 1992]. Such erosion results in the formation of large-scale filaments that stretch over midlatitude regions and ultimately mix with local air masses. Indeed, wintertime midlatitude ozone profiles are characterized by the frequent appearance of ozone filaments (or laminae), typically 1 to $2 \mathrm{~km}$ thick in the lower stratosphere [Dobson, 1973; Reid and Vaughan, 1991]. Such filaments contribute to the meridional transport of air from polar to midlatitude regions and could influence ozone trends through the transport of polar ozone-depleted air to these regions. Several studies were performed in order to evaluate the influence of these events on midlatitude ozone. Reid et al. [1998] studied

Copyright 2002 by the American Geophysical Union. 0148-0227/02/2001JD000516 in detail a set of ozone laminae, which were advected across Europe in February 1995. A photochemical trajectory model used along the laminae showed that the air was chemically activated, which had an impact on the midlatitude ozone concentrations. Norton and Chipperfield [1995] quantified the transport of chemically activated air from the Northern Hemisphere polar vortex using a three dimensional off-line chemical transport model (CTM) and the technique of contour advection. This study, which concentrates on three winters in the beginning of the nineties, indicates high interannual variation in the amount of PSC-activated air transported toward midlatitudes, ranging at $475 \mathrm{~K}$ from $50 \%$ of the total vortex mass in $1991 / 1992$ to $10 \%$ two years later.

[3] A European project, Meridional Transport of Ozone in the Lower Stratosphere, 1998/2000 (METRO), focused recently on the study of ozone laminae or vortex excursions toward midlatitudes and their influence on the meridional transport of ozone. The global objective of this project was to study the mechanisms involved in the meridional transport of air from low and high-latitude to midlatitude regions in

SOL $\quad 14-1$ 

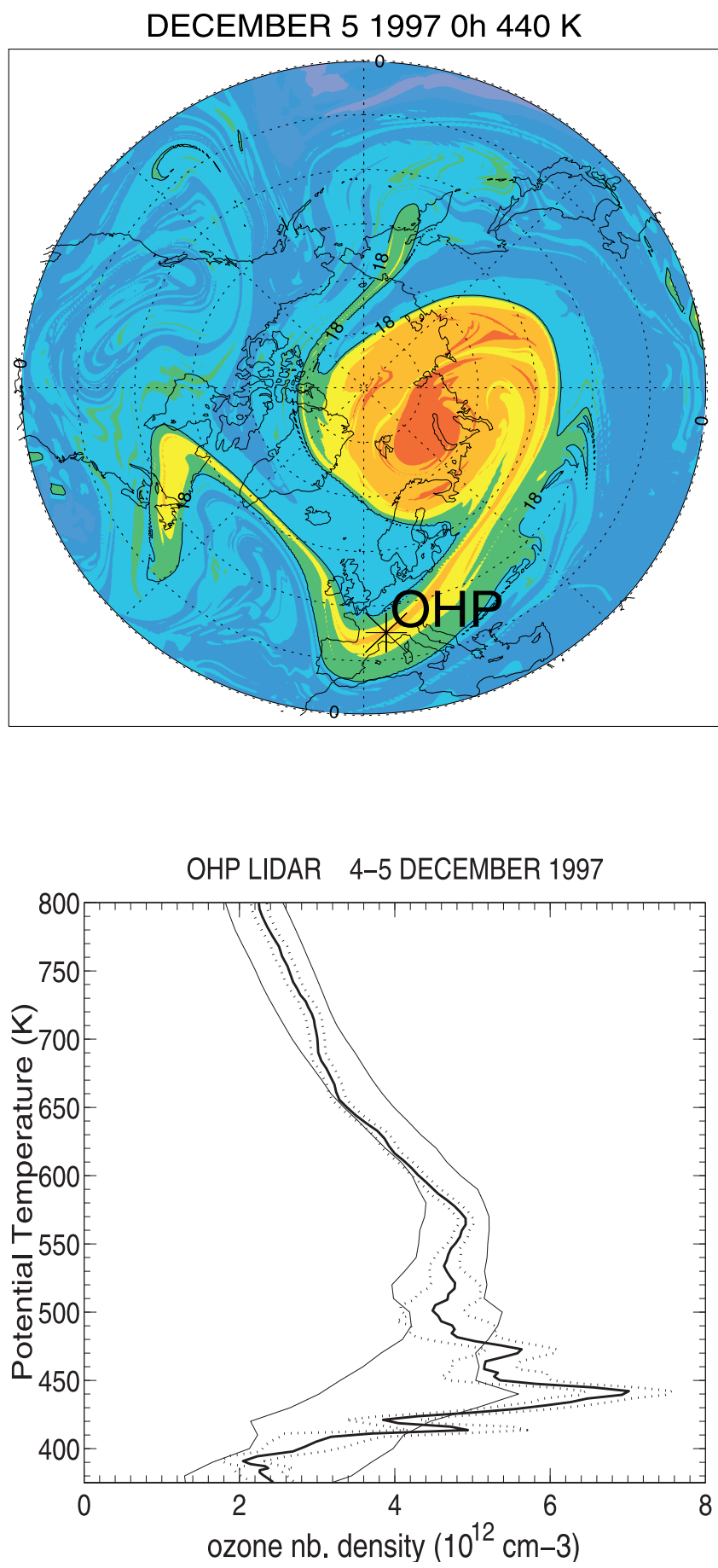

Figure 1. Top panel: high-resolution potential vorticity analysis, showing the presence of a polar filament over southern France on 5 December 1997 at 440 K. Bottom panel: lidar measurement obtained in the night of 4 December 1997, indicating an ozone-rich lamina around $440 \mathrm{~K}$. Dashed lines show $\pm 1 \sigma$ accuracy of the measurement. Thin black lines indicate $\pm 1 \sigma$ ozone average as seen by the lidar in December 1997.

the lower stratosphere, in order to understand the role of this transport on the midlatitude ozone budget. It was based on a large database of polar laminae and subtropical intrusion observations obtained from a network of ground based stations equipped with ozone lidars and ozone balloon sounding instruments as well as lidars and radars for wind profiling. The interpretation of the filament events was made using a set of high-resolution dynamical models. These models used different techniques for representing transport processes, such as contour advection with surgery [Morgenstern and Carver, 1999; Mariotti et al., 1997], high-resolution potential vorticity (PV) advection [Hauchecorne et al., 2002] and reverse domain-filling trajectory models [Orsolini et al., 1997]. In addition, an airborne ozone lidar implemented on board a French Falcon flying around $12 \mathrm{~km}$ altitude was deployed in order to investigate the size and structure of the polar and subtropical laminae predicted by the high-resolution transport models [Heese et al., 2001]. Finally, one of the high-resolution transport models used the forecast European Centre for Medium-Range Weather Forecasting (ECMWF) winds to launch alerts for the observation of polar or subtropical filaments at the ground based stations and plan the operation of the airborne lidar.

[4] The present study was motivated by the observation of a strong polar filament over Haute-Provence Observatory (OHP) during the night of 4-5 December 1997 (see Figure 1a). The high-resolution PV analysis at $440 \mathrm{~K}$ revealed the development of a large tongue of vortex air that stretched over Russia up to southern France, Ireland, Greenland and down to Canada. The filament is also seen at $475 \mathrm{~K}$, extending slightly more to the South, up to the northern African coast. The ozone profile obtained during that night at OHP is represented in Figure 1b, together with the ozone average for this month. Ozone-rich laminae are clearly visible from 410 to $480 \mathrm{~K}$ with a maximum increase of about $75 \%$ with respect to the ozone average. This observation shows that Arctic filaments can extend down to midlatitude stations such as OHP located at $44^{\circ} \mathrm{N}$, and are likely to influence ozone amounts at these stations.

[5] This paper focuses on the analysis of ozone vertical profile measurements obtained at OHP in the winters ranging from $1996 / 1997$ to $1999 / 2000$, in order to study the filamentation processes linked to polar vortex erosion. Excursions of the polar vortex above the station are also considered. For the interpretation of the observations, a high-resolution PV transport model is used, assuming that $\mathrm{PV}$ is a conserved quantity on isentropic surfaces for about 10 days and ozone in the lower stratosphere is a semi passive tracer well correlated with potential vorticity. The paper is organized as follows. It first describes the ozone vertical profile measuring techniques at OHP and shows polar filament observations within the METRO project. The method used to detect polar air events at OHP is then outlined. It uses PV fields computed by the high-resolution PV advection model. A threshold detection technique using equivalent latitude fields computed from the PV fields was designed in order to detect air masses likely to originate from the polar vortex. This analysis allows us to quantify the portion of polar air detected at OHP and study the influence of these events on the ozone amount at this location.

\section{Measurement of the Stratospheric Ozone Vertical Distribution at OHP}

\subsection{Ozone Lidar Measurements}

[6] The ozone lidar measurements are performed according to the DIAL method, which requires the emission of two 
laser wavelengths with different ozone absorption cross sections. In the case of the OHP lidar, the absorbed radiation is emitted by a $\mathrm{XeCl}$ excimer laser at $308 \mathrm{~nm}$ and the reference line is provided by the third harmonic of a Nd:Yag laser at $355 \mathrm{~nm}$ [Godin et al., 1989]. The ozone number density vertical profile is retrieved from the slope of the lidar signals obtained from the elastic Rayleigh scattering of the laser light by the atmospheric layers. For the study of ozone laminae in the lower stratosphere, the validity of the ozone lidar measurements in this altitude range is essential. In the case of lidar measurements, problems can arise if the large dynamic of the return signals is not correctly handled by the acquisition system used for recording the data (photon counting mode in our case). One has thus to check thoroughly the linearity of the lidar signals. The following procedure is used for the stratospheric ozone lidar measurements at OHP. The large dynamic of the Rayleigh lidar signals is first handled by separating each return signals into a low and a high energy channel for the measurement of ozone in the low and middle-high stratosphere, respectively. Moreover, in condition of high aerosol loading, the aerosols at the altitude of the volcanic cloud locally perturb the ozone profile. In order to solve this problem, two additional wavelengths are detected simultaneously, corresponding to the first Stokes vibrational Raman scattering by atmospheric nitrogen of the laser beams. These wavelengths allow an ozone profile to be obtained which is much less perturbed by the presence of the volcanic aerosols [McGee et al., 1994]. However, due to the smaller Raman scattering efficiency, the Raman signals are less energetic and the vertical resolution of the Raman ozone profile has to be reduced as compared to the Rayleigh one [World Meteorological Organization (WMO), 1998]. The use of the low resolution Raman ozone profile in the low stratosphere can thus prevent the detection of thin ozone laminae. In conditions of background aerosols, the ozone profile can be computed in the low stratosphere from the low energy Rayleigh signals provided that they are not saturated in the lower ranges. In order to check and eventually correct the saturation of these signals, one can use the Raman signals by comparing the slope of each low altitude Rayleigh signal to a "reference Rayleigh" slope, computed for both wavelengths from the Raman signals and the Raman ozone profile. The parameter used for the saturation correction of the Rayleigh signals is then adjusted to obtain the best fit with the "reference Rayleigh" slope. In total the lidar set up includes six optical channels and the corresponding return signals are recorded simultaneously. The lidar measurements obtained in the four winters considered in this study were processed following this procedure. During this period, the amount of stratospheric aerosols was extremely low, so the Rayleigh signals could be used down to about $14-15 \mathrm{~km}(400 \mathrm{~K})$. At this altitude, the resolution of the Raman profile is around $1.2 \mathrm{~km}$ as compared to $0.4 \mathrm{~km}$ for the Rayleigh one.

[7] The accuracy of the lidar ozone profile depends on the duration of the measurement and the vertical resolution chosen to process the data [Godin et al., 1999]. The typical duration of an ozone measurement in the whole stratosphere with the present DIAL system at OHP is 4 hours. The accuracy in the $12-30 \mathrm{~km}$ altitude domain considered here ranges from about 3 to $7 \%$ for a corresponding vertical
Table 1. Number of Lidar and Ozone Sonde Measurements

\begin{tabular}{lcccc}
\hline & $1996 / 1997$ & $1997 / 1998$ & $1998 / 1999$ & $1999 / 2000$ \\
\hline Lidar & 95 & 102 & 85 & 86 \\
Sondes & 23 & 23 & 33 & 27 \\
\hline
\end{tabular}

resolution of $0.4 \mathrm{~km}$ at 12 and $2 \mathrm{~km}$ at $30 \mathrm{~km}$. Lidar measurements of the ozone vertical distribution are expressed in ozone number density as a function of geometrical altitude. In order to convert both the ozone number density in mixing ratio and the vertical scale in potential temperature, we use pressure-temperature profiles obtained from daily radiosoundings performed in Nîmes, located at $200 \mathrm{~km}$ from OHP. The additional error resulting from this conversion is of the order of a few percents [WMO, 1998].

[8] Stratospheric lidar measurements generally require clear sky conditions, but the location of the OHP station is favorable to such measurements since an average of 150 stratospheric ozone lidar measurements are obtained per year since 1994, with a peak of 194 in 1997. Measurements are also limited to the nighttime period. The number of lidar measurements obtained from 1 November to 30 April in each winter considered in this study is indicated in Table 1. It is about 90 in average or 15 measurements per month.

\subsection{Ozone Sonde Measurements}

[9] Regular ozone soundings have been performed at OHP since 1984. At the present time, ECC ozone sondes are flown together with Vaisala meteorological sondes providing pressure, temperature and relative humidity measurements. The vertical resolution is about $0.2 \mathrm{~km}$ and the precision is estimated at $8 \%$ [Beekmann et al., 1994]. The comparison with near coincident lidar measurements shows that the accuracy of the sonde measurements is improved if a correction factor is applied. It corresponds to the ratio of the total ozone measured by a Dobson spectrophotometer located on the same site, to the total ozone derived from the sonde measurements [WMO, 1998]. The ozone residual corresponding to the ozone amount above the sonde maximum altitude is estimated using SAGE II and lidar climatologies at OHP. One ozone sounding is performed per week, but additional measurements were performed when METRO alerts were launched. The number of ozone soundings considered here is indicated in Table 1. This table shows that the lidar measurements provide a much better sampling of the ozone field, which results in a better estimation of the ozone variability.

\section{Detection of Polar Air Events Over OHP 3.1. Description of the High-Resolution Transport Model}

[10] The largest polar filaments or subtropical intrusions are likely to be discernible in the standard ECMWF fields but only high-resolution models are able to resolve the very fine structures present in the potential vorticity fields. A high-resolution transport model was developed at Service d'Aéronomie in order to predict and analyze the geographical location of polar filaments in the midlatitude regions. It is described in detail in a companion paper [Hauchecorne et al., 2002]. Briefly, the Modèle Isentropique de transport 

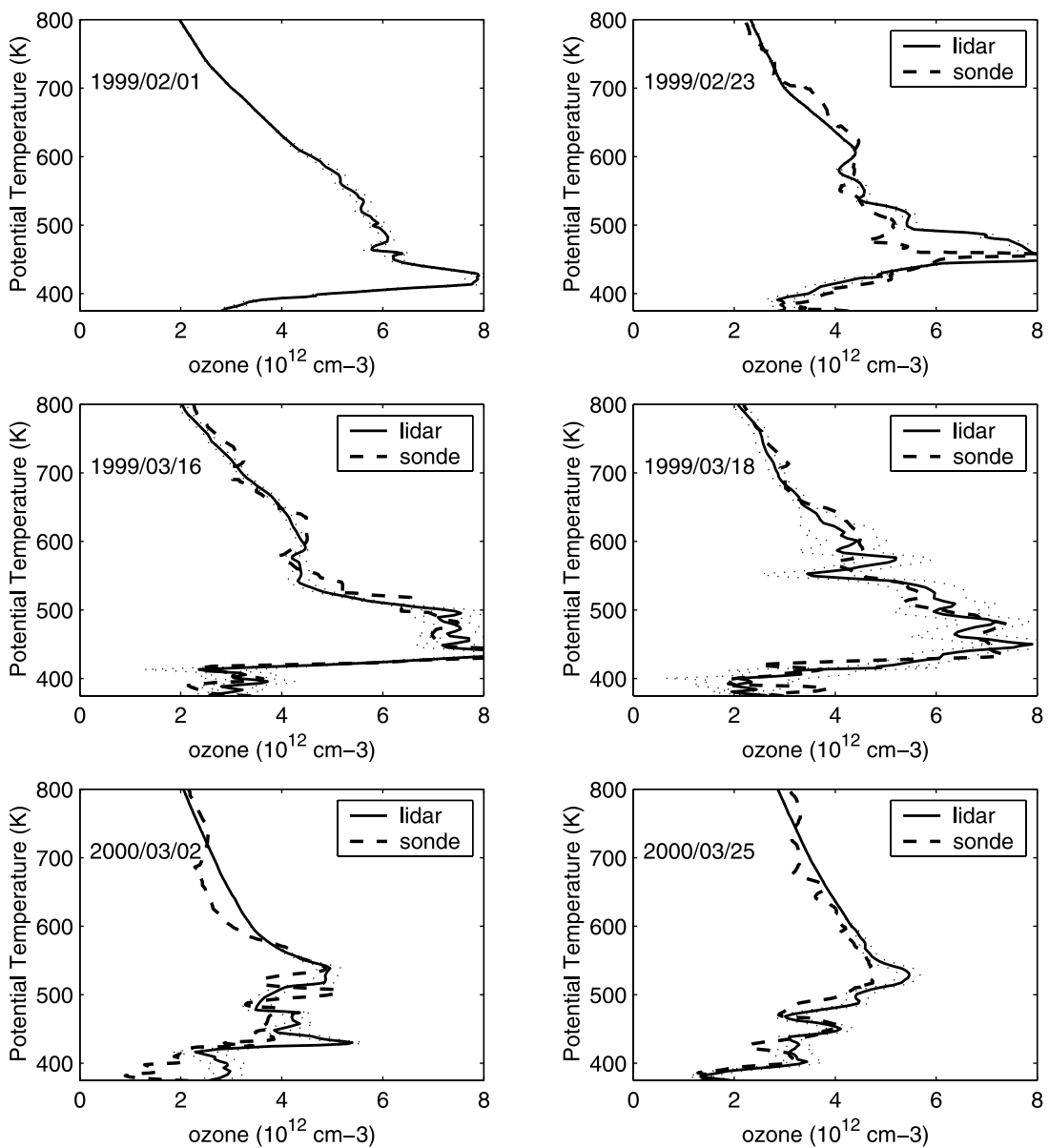

Figure 2. Examples of lidar and ozone sondes profiles obtained during METRO alerts in the winters $1998 / 1999$ and 1999/2000.

Mésoéchelle de l'Ozone Stratosphérique par Advection (MIMOSA) model is based on the advection of potential vorticity. It starts from a PV field on an isentropic surface provided by ECMWF analysis and interpolated on a fine horizontal grid that can be chosen at $3 \mathrm{pt} /$ degree or $6 \mathrm{pt} /$ degree. The PV at each grid point is advected using ECMWF winds and a reinterpolation of the PV field is made on the original grid every 12 hours in order to keep the field defined on a homogeneous rectangular grid. Daily ECMWF wind fields at 12 UT on a $2.5^{\circ} \times 2.5^{\circ}$ latitudelongitude grid are used for the advection. In order to follow the diabatic change of PV during the winter, a relaxation is applied on the model PV field toward the ECMWF PV field with a 10 days relaxation time constant. The model starts on 1 November and runs continuously until the end of April. It creates two high-resolution PV maps per day at 0 and 12 UT. The model can be run on various isentropic levels from $350 \mathrm{~K}$ upward.

\subsection{Ozone Measurements Within the METRO Project}

[11] An alert procedure was set up within the METRO project in order to optimize ozone measurements at each station involved in the project during the passage of polar filaments or subtropical intrusions. For this purpose, the MIMOSA model was run daily using ECMWF wind and PV forecast data at 12 UTC, provided by the NADIR database at the NILU data center with a resolution of $2.5^{\circ}$ in both latitude and longitude. It delivered an analysis and five days forecast of the PV distribution in the Northern Hemisphere. The model ran every morning at 5 UTC throughout the whole winter period providing forecasts about 2 hours later. If an interesting filament was forecast to occur over Europe within the following 48 hours, an alert was sent to the stations closest to the filament. At OHP the number of polar filament alerts varied considerably from one winter to the next. For example, in the winter of 1998/1999, the polar vortex was rather warm and perturbed and numerous polar filaments were detected as far south as Southern Europe. Several METRO flights were performed from Paris to the south of Italy in order to probe polar filaments extending toward these latitudes [Heese et al., 2001]. In contrast, the following 1999/2000 winter was characterized by a cold and stable vortex and very few polar filaments were observed at OHP. High PV values were detected in the beginning of March at $475 \mathrm{~K}$. They corresponded to the shifting of the Arctic vortex itself toward midlatitude European regions.

[12] Examples of ozone profiles obtained with both the lidar and the sondes during METRO alerts in the winters 1998/1999 and 1999/2000 are represented in Figure 2. The dotted lines correspond to the $1 \sigma$ uncertainty of the lidar 
measurements. In case of quasi-coincident lidar and sonde measurements, the ozone profiles generally present the same structures provided that the detected polar air event lasts long enough above the station. The lidar measurement is an average over several hours of the ozone field above OHP while the ozone sounding is a snap shot of this field at a particular time and altitude. In the night of 1-2 February 1999, a large filament was detected by the lidar around $420-440 \mathrm{~K}$. The PV map of that night (not shown) indicates the presence of a large filament originating in Siberia and stretching down to northern Italy, southern France and the west coast of Spain. Later in the month, on 23-24 February, the polar vortex was elongated down to southern Europe and both measurements obtained by lidar and ozone sounding show a layer with high ozone amount around $460 \mathrm{~K}$. The ozone sounding shows a thinner filament than the lidar. This difference can be attributed to the time difference of the measurements since the ozone sounding was performed 6 hours before the lidar measurement started. It can also be explained by the 7 hour duration of the lidar measurement; the visualization of lidar ozone profiles on $20 \mathrm{~min}$ averages shows a stable rich ozone layer around $460 \mathrm{~K}$ with a thickness varying from 50 to $100 \mathrm{~K}$. Also, the lidar vertical resolution is slightly lower than the sounding one $(0.4 \mathrm{~km}$ at this altitude compared to $0.2 \mathrm{~km}$ for the ozone sounding). The measurements performed on the night of 16-17 March 1999 show a remarkable agreement between the lidar and the sonde. The sonde profile was obtained 9 hours after the lidar profile. The MIMOSA PV analysis on 17 March at 0 hour and at $460 \mathrm{~K}$ shows that the station was located on that day beneath a large tongue of polar air extending from the vortex which had split into two parts at the beginning of March 1999. On the following days, the tongue of polar air continued to stretch over Europe due to a meridional windshear and its southernmost part remained over southern France. Two lidar and sonde measurements were performed within 1 hour of each other on 18 March. Again, both show an ozone increase in the $400-500 \mathrm{~K}$ range. Again, the agreement between both measurements is excellent despite the reduced precision of the lidar measurement linked to its short duration ( $2 \mathrm{~h} 15 \mathrm{~min}$ ) due to weather problems. The last panels of Figure 2 shows measurements obtained in the following winter. The measurements of 2-3 March (on the night of 2-3 March for the lidar and on 3 March at 10 $h$ for the sonde) were obtained when the southernmost edge of the Arctic vortex reached the South of France at the beginning of March 2000. Both profiles are typical of Arctic air with steep ozone gradients above $600 \mathrm{~K}$. Below $550 \mathrm{~K}$, ozone number densities do not exceed $6.10^{12} \mathrm{~cm}^{-3}$ in contrast with the previous winter when polar air ozone number densities reached $8.10^{12} \mathrm{~cm}^{-3}$. On 25-26 March, remaining parts of the vortex were above OHP at around $640 \mathrm{~K}$. Both measurements show a steep ozone gradient above $550 \mathrm{~K}$. Lower down, the vortex was not located above the station. Same ozone structures are again observed in both profiles.

[13] These examples demonstrate that lidar and sonde measurements can be used in the same way for the study of polar air events above midlatitude stations. Care has to be taken to restrict the lidar average ozone profile to the passage of the filament over the station. However, within the METRO project, long lasting lidar measurements over more than 10 hours were performed in order to study the duration of polar filament events over OHP. Most of these measurements show that filaments appear as a stable layer in the ozone field. This indicates that polar filaments correspond to large structures in the ozone field, which evolve slowly due to the associated meridional wind shear.

\subsection{Comparison of the ECMWF and High-Resolution Model PV Fields}

[14] In order to evaluate the ability of the MIMOSA model to accurately follow the motions of the ozone field over OHP in association with the PV temporal evolution, we superposed the ozone mixing ratio evolution obtained in January 1998 to the PV contours produced by the model. From 5 to 31 January 1998, 22 ozone lidar measurements were obtained, allowing thus a fairly detailed study of the ozone field daily variability over OHP. The top panel of Figure 3 shows the MIMOSA PV contour superposed on the ozone mixing ratio cross section while ECMWF PV contours are superposed on the bottom panel. Figure 3 indicates that the ozone daily variations are followed better by MIMOSA than by the ECMWF analyses. For instance, in contrast to ECMWF, MIMOSA slightly catches the lowering of the ozone field with respect to potential temperature around 6 January. Likewise, the large descent occurring on 20 January is much sharper and timely in the MIMOSA case; at $480 \mathrm{~K}$, a PV value of 30 is given by MIMOSA compared to 25 by the ECMWF analyses. Finally, the descent occurring at the end of the month is seen by both models but earlier than as was seen in the measurements. The subsequent ozone decrease is followed better by MIMOSA than by ECMWF. Some details are however missed by both models, such as the small ozone tongue between 500 and $520 \mathrm{~K}$ on 15 January and the poor ozone episode detected by the lidar above $450 \mathrm{~K}$ on 28 January.

\section{Statistics of Polar Air Over OHP From 1996 to 2000}

\subsection{Analysis of PV and Ozone Time Series}

[15] The previous sections showed that both the groundbased measurements and the MIMOSA model agree well with respect to the detection of polar air events. They are thus qualified for the statistical study of the occurrence of polar air above the OHP station. To that aim, potential vorticity time series around OHP were produced with the MIMOSA model at various isentropic levels in the winters ranging from 1996/1997 to $1999 / 2000$. The PV values are given at 0 and 12 hours from 1 November to 30 April each winter. Due to the meridional gradient of PV in winter, polar air events linked to the advection of polar filaments or the polar vortex above the station are characterized by high PV values. The detection of such events thus requires the evaluation of a threshold value representative of polar air. In this study, we consider as polar air the air masses included in the vortex and in the whole vortex edge. Our objective is to detect all the air masses likely to experience polar processing. Chlorine activation 

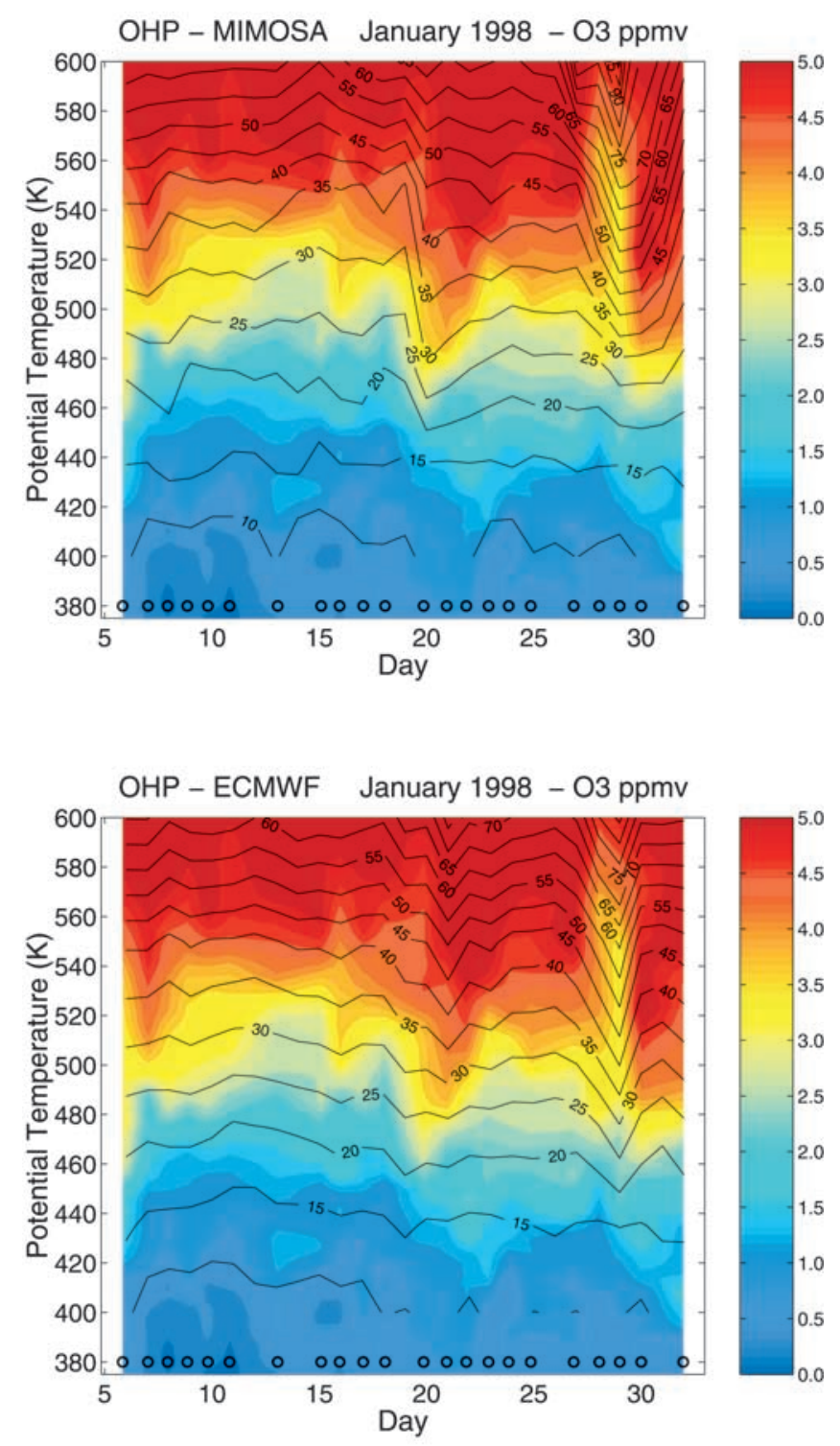

Figure 3. Top panel: temporal evolution of ozone mixing ratio as a function of potential temperature from lidar measurements at OHP in January 1998. Open circles at 380 $\mathrm{K}$ mark measurement days. The superimposed black contours show the PV temporal evolution obtained from the high-resolution MIMOSA model. Bottom panel: same as top panel except that the PV contours are from ECMWF analyses.

can also occur outside the vortex [Fierli and Hauchecorne, 2000] but this is beyond the scope of the present paper. The method used for the evaluation of the PV threshold follows the approach of Nash et al. [1996]. The potential vorticity is calculated as a function of equivalent latitude, a system of coordinates in which the pole coincides with the location of maximum potential vorticity [McIntyre and Palmer, 1984; Butchart and Remsberg, 1986]. In these coordinates, the maximum gradient of potential vorticity indicates the region of minimum mixing between the polar vortex and the surrounding regions [Chen, 1994] while the inner and outer bounds of the vortex edge are defined from the local extrema of the PV second derivative. This method was successfully used for the classification of ground-based ozone measurements obtained at the edge of the Antarctic polar vortex; it allowed the study of the seasonal variation of ozone inside, outside and in the vortex edge and the computation of ozone destruction rates inside the vortex [Godin et al., 2001].

[16] In the present study, the PV threshold value corresponds to the outer vortex edge. The algorithm used to compute this value is as follows: For each day and each isentropic level taken into consideration, PV is computed as a function of equivalent latitude. The first and second derivatives of PV are then evaluated. The threshold is defined as the PV value corresponding to the maximum in the second derivative on the lower latitude side. Due to the successive derivation processes, several maxima in the second derivative can be obtained. In this case, we compute the full width half maximum (FWHM) of the first derivative, which defines two points on each side of the maximum PV gradient. The threshold then corresponds to the equivalent latitude of the maximum in the second derivative closest to the lower equivalent latitude FWHM point. This algorithm allows us to choose the value closest to the first inflexion point of $\mathrm{PV}$ as a function of equivalent latitude (in the highlatitude side of the curve). The threshold values time series obtained are rather noisy. In order to suppress unrealistic daily variation and follow the long-term diabatic evolution of the polar vortex, the time series are smoothed with an eleven points median function and a four degree polynomial function. Finally, in order to use a more stringent criterion for polar air, we augment the final threshold value by the $1 \sigma$ standard error of the polynomial fit. In that way, we ensure that the threshold
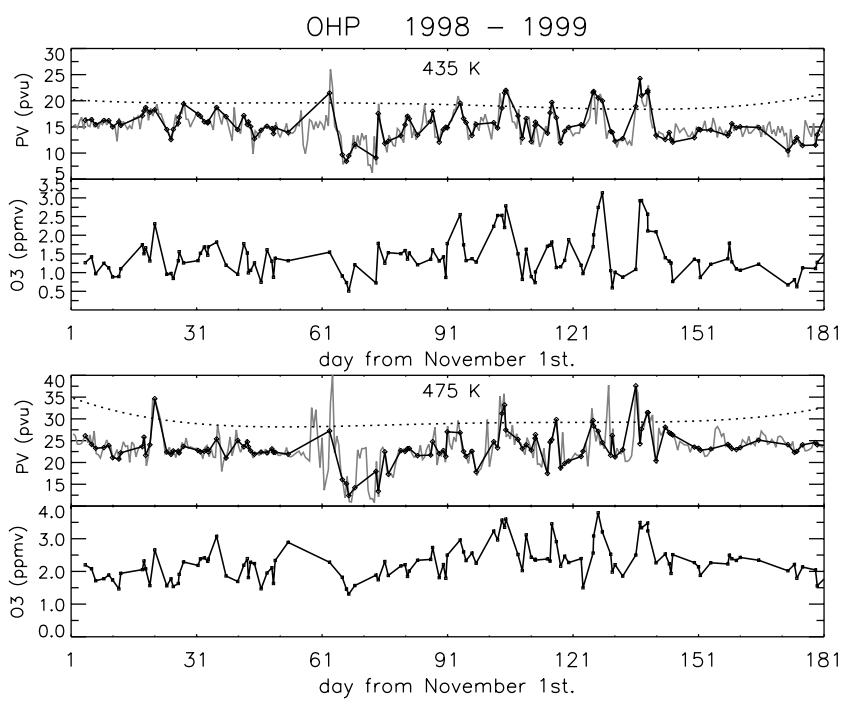

Figure 4a. Potential vorticity (top panel) and lidar ozone time series (bottom panel) at OHP at 435 and $475 \mathrm{~K}$ isentropic levels in the winter 1998/1999. Days are from 1 November. In the PV panel, the gray line indicates PV values at 0 and $12 \mathrm{~h}$, markers show PV values on lidar measurement days (at $0 \mathrm{~h}$ ) and the dashed line represents the PV threshold for the vortex air. 

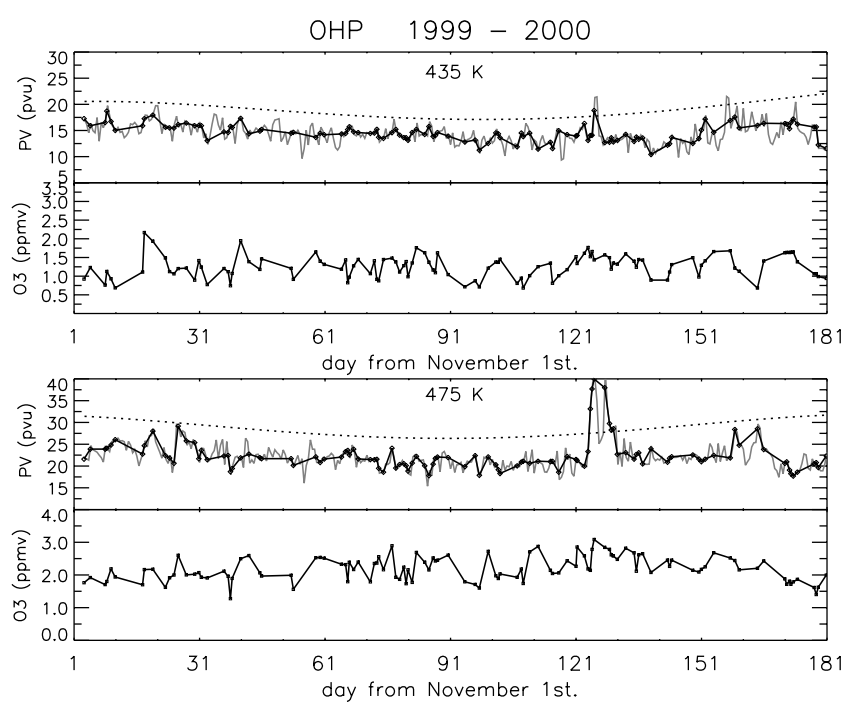

Figure 4b. Same as Figure 4a for the winter 1999/2000.

value is located on the high gradient side of the PVequivalent latitude curve.

[17] Comparison of the local PV value with the polar threshold value allows us to detect polar air events linked to a polar filament or an excursion of the polar vortex above the station. As an example, Figures $4 \mathrm{a}$ and $4 \mathrm{~b}$ show the temporal evolution of PV and ozone at 435 and $475 \mathrm{~K}$ isentropic levels in the winters of $1998 / 1999$ and 1999/2000. For each level in the figures, the top panel represents the PV time series at $0 \mathrm{~h}$ and $12 \mathrm{~h}$ and the bottom panel shows the ozone measurements obtained with the lidar and ECC sondes during that winter. Since ozone data are not obtained every day, the dark bold line in the PV panel shows PV values corresponding to the ozone measurements while the light gray line displays the whole PV time series. The dashed line represent the polar threshold values computed at each isentropic level. Both figures show that polar air events correspond to transient excursions of the local PV above the threshold. These events do not generally last more than 3 days and can thus be missed by the ozone measurements. Comparison of the OHP PV time series in Figures $4 \mathrm{a}$ and $4 \mathrm{~b}$ demonstrates the different stability of the vortex during the two winters, as mentioned in section 3 . The reduced stability of the 1998/1999 vortex is illustrated by numerous high PV events observed at both levels shown in Figure 4a. In contrast, very few peaks are observed in 1999/2000. Some relatively high PV values are detected in November. The most sizable event is detected in the beginning of March, when the polar vortex edge reached midlatitude regions in Europe. Meanwhile, the vortex was very stable and centered close to the North Pole.

[18] Due to the variation of the meridional ozone gradient with potential temperature, the polar air events are generally associated with positive ozone anomalies in the lower stratosphere and negative anomalies above $600 \mathrm{~K}$. The $500-550 \mathrm{~K}$ is a transition range linked to the reversal of the meridional ozone mixing ratio gradients. The influence of high PV events on ozone is manifest in the winter 1998/ 1999. High ozone values are detected in February and March 1999 at 435 and $475 \mathrm{~K}$ at the same time as PV increases. These events correspond to the measurements mentioned in section 3.2. In the following winter at 435 and $475 \mathrm{~K}$, the correlation is less apparent. Very few PV peaks are visible, but when one is detected by an ozone measurement, the corresponding ozone mixing ratio remains comparable to midlatitude values as in the case of the vortex excursion in the beginning of March 2000 described in section 3.2. At these levels, ozone mixing ratios are smaller in average during this last winter. They do not exceed 2 ppmv and 3 ppmv at 435 and $475 \mathrm{~K}$, respectively as compared to $3 \mathrm{ppmv}$ and $4 \mathrm{ppmv}$ in the previous winter. At higher isentropic levels, the negative correlation between ozone and PV is apparent when polar air is present above the station. This is illustrated in Figure 4c, which shows low ozone values in correlation with high PV events in the beginning of March and in April, at $675 \mathrm{~K}$.

\subsection{Evaluation of the Amount of Polar Air at OHP}

[19] In order to quantify the amount of polar air occurring above the station since 1996/1997, we computed the percentage of polar air occurring on a reference surface of $\pm 1^{\circ}$ latitude and $\pm 2^{\circ}$ longitude centered on the OHP station, at various isentropic levels. Considering the size of an elementary grid cell (the model resolution is 3 pts/degree for interannual studies), the reference surface corresponds to 91 elementary bins in the MIMOSA PV fields. At each isentropic level, the PV of each bin is compared to the daily threshold value at that level. Summing all the bins characterized by high PV values and dividing the resulting surface by the reference one allows us to determine for each day and each level the percentage of polar air detected above OHP. The evaluation of the distance between the station and the outer vortex edge on a line drawn between the station and the center of the vortex allows us to differentiate vortex excursions cases from polar filament cases. This analysis was made from 400 to $620 \mathrm{~K}$ with a resolution of $20 \mathrm{~K}$. The results are presented in Figure 5; the average percentage of polar air likely to be detected at OHP is plotted as a function of potential temperature for the four winters considered in this study. The average is made on the six winters' months, from November to April. In addition, contributions from filaments and polar excursions events to the total amount of polar air are displayed. The figure shows a large interannual variability between the various winters. In 1998/1999, the polar air fraction exceeds $5 \%$ from $440 \mathrm{~K}$ upward and reaches $15 \%$ around $560 \mathrm{~K}$. In contrast, this fraction does not exceed 4\% in the whole 400-620 K range in 1999/ 2000. Fractions of polar air observed during the two other winters are between these two extremes. Despite the inter-

$$
\text { OHP } 1999-2000
$$

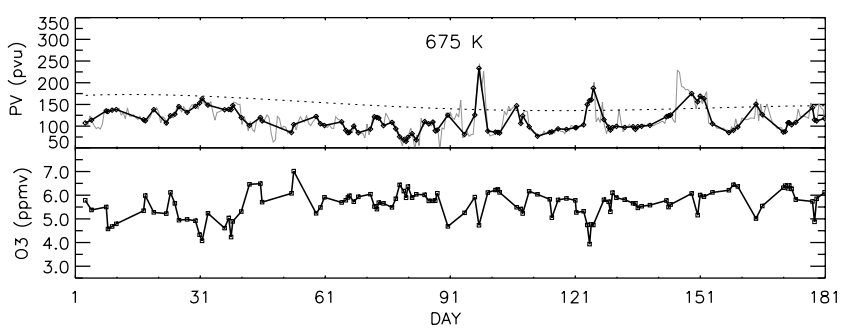

Figure 4c. Same as Figure $4 \mathrm{~b}$ for the level $675 \mathrm{~K}$. 

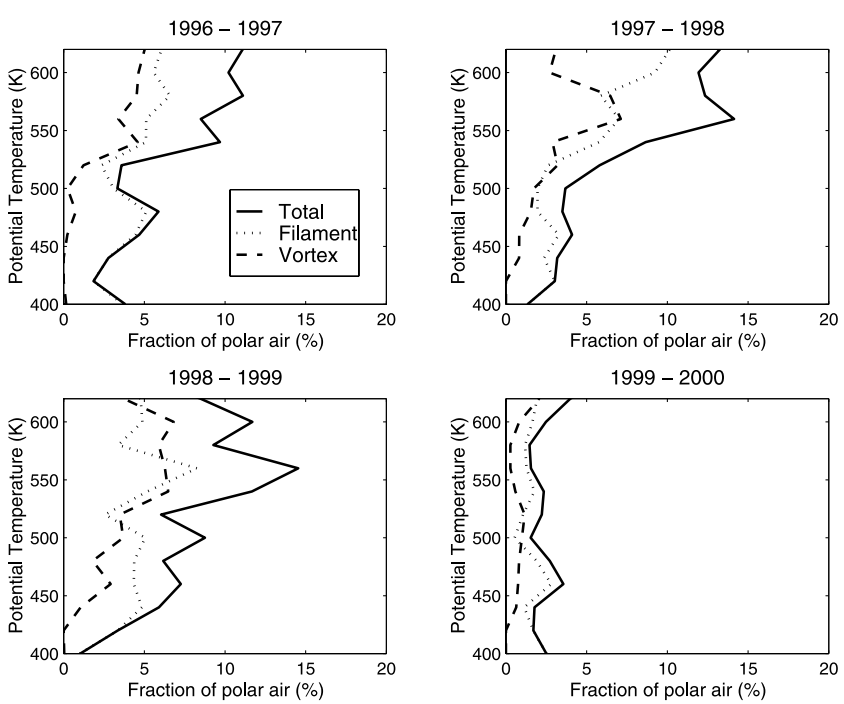

Figure 5. Fraction of polar air observed at OHP as a function of potential temperature in the winters ranging from $1996 / 1997$ to $1999 / 2000$. The dotted lines indicate the contribution of polar filaments, and the dashed lines indicate the contribution of vortex excursions.

annual variability, some features are common at least to the first three winters; the fraction of polar air generally increases with altitude, from 3 to $5 \%$ in the lower stratosphere to $10 \%$ or more above $500 \mathrm{~K}$. Furthermore, the fraction of polar air in the lower stratosphere is largely dominated by filament events, while this proportion is equally divided between the filaments and the vortex excursions in the upper levels. The increase with altitude of the fraction of polar air is in agreement with previous studies indicating that the polar vortex extends over a larger area in the middle stratosphere [Manney et al., 1993]. The development of the 1999/2000 Arctic polar vortex was studied in detail by Manney and Sabutis [2000, Figure 6]. They show that by late December, the vortex was discontinuous and larger in the upper than in the lower stratosphere. By mid-January it evolved to a strong continuous vortex, reaching lower equivalent latitudes in the middle stratosphere. Comparison with other Arctic vortex evolutions in the nineties shows that this evolution is typical of that in other cold winters. The size of the Arctic polar vortex in the middle stratosphere can be altered by minor warming that may occur in the course of the winter, as in 1998/1999, but even in that case, the vortex will eventually move toward lower latitude regions under the influence of planetary waves, which explains the fact that in general the influence of polar air on OHP ozone amounts increases with altitude.

\section{Influence of Polar Air on Ozone Amounts at OHP}

[20] Chlorine and bromine activation is likely to take place after sufficient cooling of the Arctic vortex, generally in December or January if no minor warming occurs during this period. However, large-scale ozone destruction inside the vortex does not start before sufficient sunlight is available, generally at the end of January as was observed in particular in the year 2000. In order to understand better the effect of polar air events on ozone trends at OHP, we showed in Figure 6 the total fraction of polar air seen at $\mathrm{OHP}$ as a function of month and potential temperature, in the four winters. This allows us to identify the polar air events likely to have an influence on ozone trends provided that the vortex is sufficiently cold for ozone destruction to take place. The results show that in the first three winters, large fractions of polar air are observed above the station in November and December, especially above $500 \mathrm{~K}$. In the middle stratosphere, the polar air events are dominated by vortex excursions, which can be explained by the reduced stability of the vortex during the formation period.

\subsection{Winters $1996 / 1997$ to $1998 / 1999$}

[21] In 1996/1997, the vortex was cold and stable and ozone destruction was observed inside the vortex. According to the Match technique, vortex averaged ozone loss rates reached $45 \mathrm{ppbv} / \mathrm{d}$ in early March 1997 [Schulz et al., 2000]. The ozone depletion was observed in the 400-520 $\mathrm{K}$ range. Figure 6 shows polar air events above OHP in April 1997 but they are observed above $550 \mathrm{~K}$. No significant fraction of polar air is detected in the lower stratosphere range from February to April. So it is unlikely that the Arctic ozone depletion of 1996/1997 directly influenced the ozone amount observed at OHP. In 1997/ 1998, the vortex was dynamically active and vortex excursions are observed up to January. In 1998/1999, the vortex was even warmer and polar air events are observed throughout the winter at various levels. In February, polar air above $500 \mathrm{~K}$ is essentially a result of vortex excursions while in March the distinction between vortex excursions and filaments is meaningless since the vortex split in early March as mentioned previously. During these winters, ozone chemical loss estimated by the Match technique was observed to be insignificant, except in February 1998 when an ozone loss rate of $30 \mathrm{ppbv} / \mathrm{d}$ was found around $490 \mathrm{~K}$ inside the vortex [Schulz et al., 2001]. Since no polar air was detected
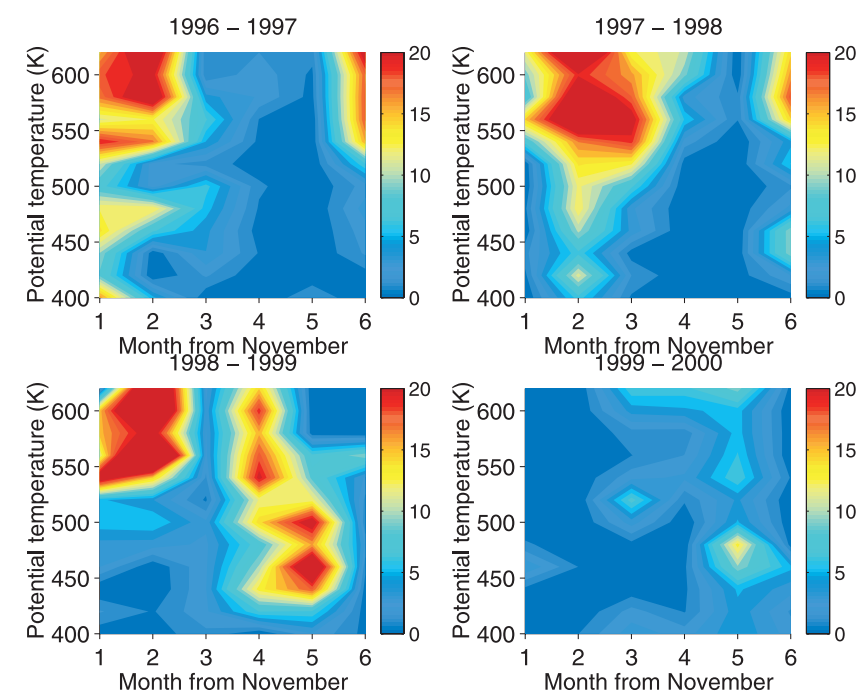

Figure 6. Percent fraction of polar air as a function of the month for the various winters since 1996/1997. 
in February 1998 at this level at OHP, it is unlikely that the polar air observed above the station during this winter was ozone depleted. Nevertheless, the polar air is likely to influence ozone trend evaluation through the transport of ozone rich air but this is part of natural ozone interannual variability. More interesting, with respect to the evaluation of chemical ozone depletion, are polar air events observed during cold winters after the conditions are set for chlorine and bromine activation inside the vortex.

\subsection{Winter $1999 / 2000$}

[22] The last winter considered in this paper is a good case study since large-scale ozone depletion was observed by various techniques in the frame of the joint Third European Stratospheric Experiment on Ozone (THESEO) and the American SAGE III Ozone Loss and Validation Experiment (SOLVE) campaigns. According to the Match technique, the ozone chemical loss reached $70 \%$ in a $1 \mathrm{~km}$ thick layer around $450 \mathrm{~K}$ in March [Rex et al., 2000]. This result was in good agreement with other methods using POAM III measurements and three-dimensional chemical transport model (3D CTM) simulations [Hoppel et al., 2002] or HALOE ozone data combined with passive tracer measurements [Müller et al., 2002]. During that winter, polar air was indeed detected at OHP in the right potential temperature range and time period likely to bring ozonedepleted air above the station. In January and February, monthly average polar air fractions larger than 5\% are visible above $500 \mathrm{~K}$. These results correspond to vortex excursions above OHP at the end of January and beginning of February. According to airborne submillimeter radiometer (ASUR) measurements, chlorine was already activated in January [von König et al., 2000] and the Match technique shows ozone loss rates of $35 \mathrm{ppbv} / \mathrm{d}$ from 480 to $580 \mathrm{~K}$ during this period [Rex et al., 2000]. Ozone loss reaching $25 \%$ in the $500-700 \mathrm{~K}$ range in the same period of time were deduced from POAM III measurements. These vortex excursions may thus have brought polar ozonedepleted air above OHP depending on the extent of the activated air region within the vortex. In March, a larger monthly average polar air fraction exceeding $10 \%$ is found above the station, at a period when the vortex is widely depleted in ozone. It corresponds to a vortex excursion affecting the whole $400-650 \mathrm{~K}$ range in the beginning of the month. As mentioned in section 3.2, the ozone measurements performed during these events show ozone values of less than 3 ppmv, which is small compared to measurements in previous years made in the same conditions, but still higher than ozone values measured deep inside the vortex by other instruments. Previous estimates of Arctic ozone losses in 2000 were calculated as an average over the vortex. They can therefore not be used for the evaluation of the ozone loss at the edge of the vortex. In order to evaluate the ozone loss associated with the polar air events detected above OHP in the beginning of the year 2000, we used the results of the simulation of the winter 1999/2000 by the 3D CTM Reactive Processes Ruling the Ozone Budget in the Stratosphere (REPROBUS). The simulated vertical ozone distribution at the OHP location compare quite well with the ozone measurements. At $475 \mathrm{~K}$, the difference with the measurements lies within $\pm 10 \%$. In such simulations, the polar ozone loss at a particular isentropic level is computed from the difference between ozone and a passive ozone tracer [Lefèvre et al., 1998]. However, since REPROBUS has a much lower resolution $\left(2^{\circ} \times 2^{\circ}\right)$ than MIMOSA, the ozone loss computed by REPROBUS above OHP on the days when polar air is detected above this station, is not necessarily representative of polar ozone loss. So we discriminated polar air in the REPROBUS PV fields in the $40-50^{\circ} \mathrm{N}$ latitude band, using the same method as described in section 4 and calculated the average ozone loss on the corresponding points. In this way, we estimate the ozone loss at the edge of the polar vortex. The ozone loss on the days when no polar air is detected in the $40-50^{\circ} \mathrm{N}$ latitude band is interpolated from previous and following days. In January and February, an ozone loss of around 12\% is found with this method at the altitude range of the vortex excursions. During the polar air event of March, the ozone loss reaches $18 \%$ in the $430-550 \mathrm{~K}$ potential temperature range. In order to determine the total ozone loss above OHP due to polar air excursions during that winter, we multiply for each day the polar ozone loss estimated by REPROBUS by the polar air fraction detected at OHP. The ozone loss is then averaged over the $400-650 \mathrm{~K}$ potential temperature range and over each month, in order to compare with estimated ozone trends in the lower stratosphere. Our results provide an estimate for the ozone loss of $0.3 \%$ in January and February and $1 \%$ in March in the $400-650 \mathrm{~K}$ potential temperature range. The total ozone decrease due to polar air events above OHP in the January-March 2000 period is thus estimated at $1.6 \%$ in the lower stratosphere.

[23] This estimate depends on the chosen definition for the threshold value. A sensitivity study was performed with threshold values corresponding to the polynomial fit itself as described in section 4.1. In this study, the threshold decreases by about $1 \mathrm{PV}$ unit ( $\mathrm{pvu}$ ) at $480 \mathrm{~K}$ and is closer to the inflexion point of $\mathrm{PV}$ as a function of equivalent latitude. The new threshold yields a polar air fraction of $16 \%$ at 480 $\mathrm{K}$ in March 2000, which is close to the previous estimate of $14 \%$ at the same level. This indicates that in the case of a strong and stable vortex, the threshold value, according to its definition, is rather stable. This was not the case in the winter 1998/1999, for which the same sensitivity study provides a 3 pvu difference between both threshold values at $480 \mathrm{~K}$. Our estimate of ozone loss in the year 2000 depends also on the ability of the REPROBUS model to compute the polar ozone loss at the vortex edge. Such simulation can indeed underestimate the ozone loss at the vortex edge due to numerical diffusion. They can also miss some polar filaments since only large filaments are visible in the meteorological fields used by these models. Highresolution simulations are thus needed to provide more accurate evaluation of ozone loss at the vortex edge and in polar filaments. Such simulation would also help differentiate the chemical influence of polar filaments and polar vortex excursions on midlatitude ozone trends. The effect of filaments is indeed more complex. They can transport polar activated air toward midlatitude with ozone destruction taking place during the advection or they can directly export polar ozone-depleted air. The former case is likely to occur soon after chlorine activation starts within the vortex, while the latter is expected to be significant when ozone depletion is widely spread within the vortex, generally from the end of February. Chlorine deactivation has also to be considered, 
which depends on the amount of denitrification inside the vortex. A coupling of the REPROBUS chemical scheme with the high-resolution transport model MIMOSA has been developed recently. First results show a larger ozone destruction inside the vortex than obtained by REPROBUS and larger ozone loss in the polar air extending toward midlatitudes from the beginning of March 2001 [Marchand et al., 2002].

\section{Conclusion}

[24] The ozone field above a midlatitude station like OHP is likely to be influenced by Arctic ozone depletion, but this influence is highly variable from one winter to the next. From the study of past four winters, the following picture emerges: When the vortex is dynamically active, large fractions of polar air are observed at midlatitude due to frequent polar filament and vortex excursion events. However, Arctic ozone depletion is limited in such conditions and the transport of ozone-depleted air above OHP is marginal. In contrast, a cold vortex is very stable and polar air events above midlatitude stations are less frequent. Nevertheless, each polar filament or vortex excursion is likely to bring ozone-depleted air above the station as soon as the vortex becomes activated. In case of very strong ozone depletion as was observed in 2000, a maximum monthly average ozone loss of $1 \%$ in the lower stratosphere was estimated in March. The different polar air events detected from January to March above the station result in a total $1.6 \%$ ozone loss in the winter 2000 in the $400-650 \mathrm{~K}$ potential temperature range. This is significant and has to be compared to a $7 \%$ decrease per decade deduced from long term ozone sonde measurements in Europe from March to May in the 200-50 hPa range, from 1970 to 1996 [see $W M O, 1998$, Figure 3.38].

[25] This study focused on the ozone loss linked to polar filaments or vortex excursions observed at OHP. It showed that due to their transient character, such polar air events can be missed by ground-based measurements, and the ozone decrease due to Arctic ozone depletion can thus be underestimated by the measurements. Otherwise, one has also to take into account the dilution effect of the vortex erosion as ozone-depleted filaments mix with surrounding midlatitude air masses. This process should affect midlatitude ozone amounts but its evaluation is difficult from ground-based measurements at one location only. Such a study will be made using the coupled MIMOSA-REPROBUS model mentioned in section 5. The ozone loss due to the final dilution of the vortex was also not considered here. It is generally missed by ground-based measurements at OHP except at a single occasion when remnants of the polar vortex passed above the station in April 1996. Evaluation of the effect of the vortex dilution was the object of previous studies using reverse-domain filling trajectory calculations [Knudsen and Gross, 2000]. The average midlatitude stratospheric ozone depletion due to this effect is estimated to be $40 \%$ of the total ozone depletion from 1979.

[26] In conclusion, strong ozone depletion within the Arctic vortex combined with transient excursions of polar air can have a significant impact on ozone amounts in the midlatitude regions. However, depletions of the kind observed in the year 2000 do not occur each winter and the ozone loss observed in the lower stratosphere at OHP was preceded by high ozone average values observed the two winters before. Nevertheless, concern could arise if an increased greenhouse effect cools the Arctic stratosphere and leads to a more stable and colder vortex in the future, as some of the ones observed in the past decade.

[27] Acknowledgments. The authors wish to thank the whole lidar team at the Observatoire de Haute-Provence and especially Philippe Gildwarg, Frédéric Gomez, Gilles Kaczmarek, and Christian Mollet for the operation of the stratospheric ozone lidar at the Observatoire de HauteProvence. They thank Anne Garnier for the technical coordination of the lidar measurements at OHP, Jacques Porteneuve, Philippe Weill, Jean-Louis Conrad, Christian Laqui, Frederic Fassina, André Théodon, and Christian Blaise for the technical support. They are grateful to Gérard Velghe and Pierre Da Conceiçao for the launching of the ozone sondes and Claude Vialle for the processing and the provision of the ozone sondes data. They thank Birgit Heese and Philippe Keckhut for the organization of the METRO alerts. This work was supported by EC contract METRO ENV4-CT97-0520.

\section{References}

Beekmann, M., G. Ancellet, G. Mégie, H. G. J. Smit, and D. Kely, Intercomparison campaign for vertical ozone profile including electrochemical sondes of ECC and Brewer-Mast type and a ground-based UV-differential absorption lidar, J. Atmos. Chem., 19, 259-288, 1994.

Butchart, N., and E. Remsberg, The area of the polar vortex as a diagnostic for tracer transport on an isentropic surface, J. Atmos. Terr. Phys., 43, 1319-1339, 1986.

Chen, P., The permeability of the Antarctic vortex edge, J. Geophys. Res., 99, 20,563-20,571, 1994.

Dobson, G. M. B., The laminated structure of the ozone in the atmosphere, Q. J. R. Meteorol. Soc., 99, 599-607, 1973.

Fierli, F., and A. Hauchecorne, Transport of chemically activated air to middle latitudes: Northern Hemisphere 1995 to 1997 winters, paper presented at SPARC 2000 2nd General Assembly, Stratos. Processes and Their Role in Clim., World Clim. Res. Prog., Mar Del Plata, Argentina, 6-10 Nov. 2000.

Godin, S., G. Mégie, and J. Pelon, Systematic lidar measurements of the stratospheric ozone vertical distribution, Geophys. Res. Lett., 16, $547-$ $550,1989$.

Godin, S., et al., Ozone differential absorption lidar algorithm intercomparison, Appl. Opt., 38, 6225-6236, 1999.

Godin, S., V. Bergeret, S. Bekki, C. David, and G. Mégie, Study of the interannual ozone loss and the permeability of the Antarctic Polar Vortex from long-term aerosol and ozone lidar measurements in Dumont d'Urville $\left(66.4^{\circ}, 140^{\circ} \mathrm{S}\right), \mathrm{J}$. Geophys. Res., 106, 1311-1330, 2001 .

Hauchecorne, A., S. Godin, M. Marchand, B. Heese, and C. Souprayen, Quantification of the transport of chemical constituents from the polar vortex to midatitudes in the lower stratosphere using the high-resolution advection model MIMOSA and effective diffusivity, J. Geophys. Res., 107, 10.1029/2001JD000491, in press, 2002.

Heese, B., S. Godin, and A. Hauchecorne, Forecasts and simulation of stratospheric ozone filaments: A validation of a high-resolution potential vorticity advection model MIMOSA by airborne lidar measurements in winter 1998/1999, J. Geophys. Res., 106, 20,011-20,024, 2001.

Hoppel, K., R. M. Bevilacqua, G. Nedoluha, C. Deniel, F. Lefevre, J. D. Lumpe, M. D. Fromm, C. E. Randall, J. E. Rosenfield, and M. Rex, POAM III observations of Arctic ozone loss for the 1999/2000 winter, J. Geophys. Res., 107, 10.1029/2001JD000476, in press, 2002.

Knudsen, B. M., and J.-U. Gross, Northern midlatitude stratospheric ozone dilution in spring modeled with simulated mixing, J. Geophys. Res., 105, 6885-6890, 2000.

Lefèvre, F., F. Figarol, K. S. Carslaw, and T. Peter, The 1997 Arctic ozone depletion quantified from three-dimensional model simulations, Geophys. Res. Lett., 25, 2425-2428, 1998.

Manney, G. L., and J. L. Sabutis, Development of the polar vortex in the 1999-2000 Arctic winter stratosphere, Geophys. Res. Lett., 27, 25892592, 2000

Manney, G. L., and W. Z. Zureck, Interhemispheric comparison of the development of the stratospheric polar vortex during fall: A 3-dimensional perspective for 1991-1992, Geophys. Res. Lett., 20, 1275$1278,1993$.

Marchand, M., S. Godin, A. Hauchecorne, F. Lefèvre, and S. Bekki, Influence of polar ozone loss on northern midlatitude regions estimated by a 
high-resolution chemistry transport model during winter 1999/2000, J. Geophys. Res., 107, 10.1029/2001JD000906, in press, 2002.

Mariotti, A., M. Moustaoui, B. Legras, and H. Teitelbaum, Comparison between vertical ozone, soundings, reconstructed potential vorticity maps by contour advection with surgery, J. Geophys. Res., 102, 6131-6142, 1997.

McGee, T. J., P. Newman, M. Gross, U. Singh, S. Godin, A. M. Lacoste, and G. Mégie, Correlation of ozone loss with the presence of volcanic aerosols, Geophys. Res. Lett., 21, 2801-2804, 1994.

McIntyre, M. E., and T. N. Palmer, The 'surf zone' in the stratosphere, $J$. Atmos. Terr. Phys., 9, 825-849, 1984.

Morgenstern, O., and G. D. Carver, Quantification of filaments penetrating the subtropical barrier, J. Geophys. Res., 104, 31,275-31,286, 1999.

Müller, R., et al., Chlorine activation and chemical ozone loss deduced from HALOE and balloon measurements in the Arctic during the winter of 1999/2000, J. Geophys. Res., 107, 10.1029/2001JD001423, in press, 2002.

Nash, E. R., P. A. Newman, J. E. Rosenfield, and M. E. Schoeberl, An objective determination of the polar vortex using Ertel's potential vorticity, J. Geophys. Res., 101, 9471-9478, 1996.

Norton, W. A., and M. P. Chipperfield, Quantification of the transport of chemically activated air from the Northern Hemisphere polar vortex, $J$. Geophys. Res., 100, 25,817-25,840, 1995.

Orsolini, Y. J., G. Hansen, U.-P. Hoppe, G. L. Manney, and K. H. Fricke, Dynamical modelling of wintertime lidar observations in the Arctic: Ozone laminae and ozone depletion, Q. J. R. Meteorol. Soc., 123, $785-800,1997$.

Reid, S. J., and G. Vaughan, Lamination in ozone profiles in the lower stratosphere, Q. J. R. Meteorol. Soc., 117, 825-844, 1991.

Reid, S. J., et al., A study of ozone laminae using diabatic trajectories, contour advection and photochemical trajectory model simulations, $J$. Atmos. Chem., 30, 187-207, 1998.

Rex, M., R. Lehrmann, R. J. Salawitch, M. L. Santee, and J. W. Wtares, Theory and observations of Arctic ozone loss rates, paper presented at the Quadrennial Ozone Symposium, Int. Ozone Comm., Sapporo, Japan, 2000.

Schulz, A., et al., Match observations in the Arctic winter 1996/97: High stratospheric ozone loss rates correlate with low temperatures deep inside the polar vortex, Geophys. Res. Lett., 27, 205-208, 2000.

Schulz, A., et al.. Arctic ozone loss in threshold conditions: Match observations in 1997/1998 and 1998/1999, J. Geophys. Res., 106, 7495-7503, 2001.

Tuck, A. F., et al., Polar stratospheric cloud processed air and potential vorticity in the Northern Hemisphere lower stratosphere at midlatitudes during winter, J. Geophys. Res., 97, 7883-7904, 1992.

von König, M., H. Bremer, A. Goede, A. Kleinböhl, H. Küllmann, K. Künzi, and G. Toon, Evolution of chlorine activation during Arctic winter $1999 / 2000$ as measured by the Airborne Submillimeter Radiometer ASUR, paper presented at the SOLVE/THESEO 2000 Science Meeting, Eur. Comm., Natl. Aeronaut. and Space Admin., Palermo, Italy, 25-29 Sept. 2000.

World Meteorological Organization, Assessment of Trends in the Vertical Distribution of Ozone, Rep. 43, Geneva, 1998.

S. Godin, A. Hauchecorne, F. Lefèvre, and M. Marchand, Service d'Aéronomie CNRS, Université P.M. Curie, B. 102, 4 Place Jussieu, F-75230 Paris, Cedex05, France. (sophie.godin@aero.jussieu.fr; alain.hauchecorne@ aerov.jussieu.fr; franck.lefevre@meteo.fr; marion.marchand@aero.jussieu. fr) 